\title{
COPE Newsletter: In the news April 2020
}

\author{
Nancy Chescheir, COPE Council Member
}

30 March 2020

$$
|\mathrm{G}| \mathrm{O}|\mathrm{P}| \mathrm{E} \mid
$$

https://publicationethics.org/news/news-april-2020

\section{Diversity \& Inclusion}

In a study of gender bias in 145 journals in various areas of research, including 1.7 million authors and 740,00 referees, these authors show that in biomedicine and health journals women authors were treated generally favourably by editors and reviewers. This is in contrast to social science and humanity journals. The authors advocate for gender diversity among reviewers and editors to mitigate the perception and reality of bias.

\section{https://osf.io/preprints/socarxiv/gh4rv/}

The investment bank and financial services company Goldman Sachs recently announced it will no longer take companies public unless they have at least one diverse board member because diversity inherently "reduces the risk of groupthink and unlocks creative and impactful solutions".

www.goldmansachs.com/what-we-do/investing-and-lending/launch-with-gs/pages/commitment-todiversity.html

The journal Development and its publisher, both COPE members, recently launched an inclusive directory of developmental and stem cell biologists called "Node Network." It is intended to promote diversity by helping people find conference speakers, peer reviewers, and more.

https://thenode.biologists.com/networkinfo/

\section{Preprints}

In December 2019, the Preprints I/O Workshop explored ways to expand and leverage the preprint platform.

https://medium.com/@cziscience/strengthening-the-open-science-ecosystem-through-preprints9e87969631ba 
This is a report from a survey of 44 platforms that host preprints relevant to life and biomedical sciences and that were active online and accepting submissions on 25 June 2019. Data are separated into five main tables of information and a list of preprint platform websites for reference:

- Scope and ownership of each server

- Content-specific characteristics and information relating to submission, journal transfer options, and external discoverability

- Screening, moderation, and permanence of content

- Usage metrics and other features

- Metadata

Preprint platform websites

https://zenodo.org/record/3612693\#.XigryBP7Qyk

COPE Council member, Iratxe Puebla published a blog post on ASAPbio about COPE guidance document on preprints, highlighting the importance of transparency about preprint publication processes and using the guidance for initiating important conversations about preprints.

\section{https://asapbio.org/cope-discussion}

The authors did two comparisons: samples of biomedical papers published in 2016 on BioRxiv preprint server compared to peer reviewed publication and second, the preprint compared to journal publication of the same research. They conclude that there is about a $5 \%$ increase in quality in the peer reviewed journal, but that this small difference supports the conclusion that preprints should be considered valid scientific contributions.

https://www.biorxiv.org/content/10.1101/581892v2

\section{Open Science/Open Humanities}

Just over 60 of about 400 mostly European research funders responding to a 2019 survey of their policies regarding open science and how they reward and incentivise their researchers to adopt open practices. While in general, the agencies and organisations favour greater openness, the extent of which they have operationalised this direction varies.

https://scholarlykitchen.sspnet.org/2020/02/26/guest-post-an-open-agenda-european-funderapproaches-to-open-science/

UK universities and Wiley have struck a 4 year deal which will give UK-based corresponding authors the option to publish open access at no extra cost; their universities will pay the publisher based on the number of articles published - the so-called "publish and read" model - rather than paying subscriptions for access.

https://www.timeshighereducation.com/news/wiley-strikes-read-and-publish-deal-uk-universities 
Fundamental characteristics of open science do not translate to "open humanities". Marcel Knöchelmann argues that researchers in the humanities should develop a unified voice and vision for open humanities, without which they will be vulnerable to top-down reforms.

https://blogs.Ise.ac.uk/impactofsocialsciences/2020/02/25/open-humanities-why-open-science-inthe-humanities-is-not-enough/

\section{China}

Chinese Research Policy for STEM research and higher education.

https://scholarlykitchen.sspnet.org/2020/02/27/new-chinese-policy-could-reshape-global-stmpublishing/

https://scholarlykitchen.sspnet.org/2020/03/03/guest-post-how-chinas-new-policy-may-changeresearchers-publishing-behavior/

In early 2020, the Chinese government issued 2 policies that will have significant influence on STEM researchers and higher education evaluation systems. These reduce the burden of "publish or perish" by eliminating or reducing emphasis on the Journal Impact Factor and Science Citation Index of published work in recruitment and promotion actions. Publishing in high quality Chinese journals will be expected.

https://www.timeshighereducation.com/news/chinese-government-bulldozes-publish-or-perishmentality\#survey-answer

\section{Misconduct}

The editor of Molecular Brain tracked responses by authors of 41 papers for which the data appeared "too beautiful" to the request for the raw data. Twenty authors withdrew their submission and 19 provided insufficient data to support the results. The editor makes an argument that lack of data is a contributor to the reproducibility crisis.

https://molecularbrain.biomedcentral.com/articles/10.1186/s13041-020-0552-2

A web of papers that involves spider biologist Jonathan Pruitt has become increasingly complicated. His lawyers have asked institutions, journals, and collaborators to allow the retraction process as articulated by COPE Guidance to play out before taking action.

https://www.sciencemag.org/news/2020/03/embattled-spider-biologist-seeks-delay-additionalretractions-problematic-papers

\section{Research Culture}

Learned Publishing also recently published a special issue dedicated to society publishing. Articles describe an industry in transition and how different organizations are responding to current challenges.

https://onlinelibrary.wiley.com/toc/17414857/2020/33/1 
Wellcome commissioned a review of research culture, including literature review, qualitative interviews and surveys. This report,"What Researchers Think About the Culture they work in" explores the findings.

https://wellcome.ac.uk/sites/default/files/what-researchers-think-about-the-culture-they-work-in.pdf

An analysis of $>2,000$ published retractions show that about $15 \%$ were by the authors themselves. Even with adequate notices, $91 \%$ of retracted articles did not comply with COPE recommendations for retraction transparency and content.

https://blogs.Ise.ac.uk/impactofsocialsciences/2020/02/20/retractions-the-good-the-bad-and-theugly-what-researchers-stand-to-gain-from-taking-more-care-to-understand-errors-in-the-scientificrecord/

Gamifying learning about research integrity. Researchers at Erasmus University are collecting new scenarios to add to their app "Dilemma Game" which will encourage participants to discuss issues relating to professionalism and integrity in research. If you want to submit a personal experience, the link below will show you how.

A survey of 55 Canadian and American academics revealed varied priorities for publishing decisions and their perceived importance within review, promotion, and tenure (RPT). Variation exists between what the respondents think and what they believe their peers think, as well as between tenured and untenured respondents.

https://journals.plos.org/plosone/article?id=10.1371/journal.pone.0228914

\section{Predatory Publishing}

IGI Global has published a series of related articles and resources to help combat Predatory or Fake publications. This issue includes a description of the Texas Tech education program about open access and predatory publishing and also a paper about secrets of predatory publishers.

https://www.igi-global.com/newsroom/archive/fight-against-predatory-publishing-gaining/4438/

\section{Coronavirus}

As the Coronavirus pandemic further develops, the role of open science is coming to the fore: an editorial in Nature urged researchers to "keep sharing, stay open". This report highlights some of the ways the research communities informing our knowledge about SARS-COVID-19 are working together through open science methods, as well as some of the reasons this is such an important moment in biomedicine.

http://theconversation.com/the-hunt-for-a-coronavirus-cure-is-showing-how-science-can-change-forthe-better-132130

Science Open has an automatically updating Collection of published research on Coronavirus Disease (Covid 19) including terms COVID-2019, SARS-CoV-2, 2019-nCoV. Caution: articles flagged as "preprint" have not yet undergone peer review.

https://blog.scienceopen.com/2020/03/covid-19-resources/ 


\section{References}

Squazzoni, F., Bravo, G., Dondio, P., Farjam, M., Marusic, A., Mehmani, B., ... Grimaldo, F. (2020, March 2). No evidence of any systematic bias against manuscripts by women in the peer review process of 145 scholarly journals. SocArxiv; https://doi.org/10.31235/osf.io/gh4rv

Solomon, D. (2020). Goldman Sachs' Commitment to Board Diversity. Launch With GS (Feb. 4). Retrieved from: https://www.goldmansachs.com/what-we-do/investing-and-lending/launchwith-gs/pages/commitment-to-diversity.html

The Company of Biologists. (2020). The Node Network. https://thenode.biologists.com/networkinfo/

Chan Zuckerberg Science Initiative. (2020). Strengthening the Open Science Ecosystem Through Preprints. Medium. Retrieved from: https://cziscience.medium.com/strengthening-the-openscience-ecosystem-through-preprints-9e87969631ba

Penfold, N. C, Murphy, F. L. M, \& Kirkham, J. J. (2020). Practices and policies of preprint platforms for life and biomedical sciences. Zenodo. DOI: 10.5281/zenodo.3612693.

Puebla, I. (2020). Preprints and ethical publishing practice: COPE's Discussion document as a stepping stone to best practice guidelines. ASAPbio. https://asapbio.org/cope-discussion

Carneiro, C. F. D., et al. (2020). Comparing quality of reporting between preprints and peer-reviewed articles in the biomedical literature. bioRxiv 581892; doi: https://doi.org/10.1101/581892

Johnson, R., \& Proudman, V. (2020). An Open Agenda: European Funder Approaches to Open Science. The Scholarly Kitchen. https://scholarlykitchen.sspnet.org/2020/02/26/guestpost-an-open-agenda-european-funder-approaches-to-open-science/

THE. (2020). Wiley strikes 'read-and-publish' deal with UK universities.

https://www.timeshighereducation.com/news/wiley-strikes-read-and-publish-deal-ukuniversities

Knöchelmann, M. (2020). Open Humanities: Why Open Science in the Humanities is not Enough. LSE Impact of Social Sciences. Retrieved from:

https://blogs.Ise.ac.uk/impactofsocialsciences/2020/02/25/open-humanities-why-openscience-in-the-humanities-is-not-enough/

Tao, T. (2020). New Chinese Policy Could Reshape Global STM Publishing. The Scholarly Kitchen. https://scholarlykitchen.sspnet.org/2020/02/27/new-chinese-policy-could-reshape-globalstm-publishing/

Xu, J. (2020). How China's New Policy May Change Researchers' Publishing Behavior. The Scholarly Kitchen. https://scholarlykitchen.sspnet.org/2020/03/03/guest-post-how-chinas-newpolicy-may-change-researchers-publishing-behavior/

THE. (2020). Chinese government bulldozes 'publish or perish' mentality. https://www.timeshighereducation.com/news/chinese-government-bulldozes-publish-orperish-mentality\#survey-answer 
Miyakawa, T. (2020). No raw data, no science: another possible source of the reproducibility crisis. Mol Brain 13, 24. https://doi.org/10.1186/s13041-020-0552-2

Pennisi, E. (2020). Embattled spider biologist seeks to delay additional retractions of problematic papers. Science News. doi:10.1126/science.abb7068

Learned Publishing. (2020). https://onlinelibrary.wiley.com/toc/17414857/2020/33/1

Wellcome. (2020). What Researchers Think About the Culture they work in. https://wellcome.org/sites/default/files/what-researchers-think-about-the-culture-they-workin.pdf

Vuong, Q. H. (2020). Retractions: the good, the bad, and the ugly. LSE Impact of Social Sciences (Feb 20, 2020). https://blogs.Ise.ac.uk/impactofsocialsciences/2020/02/20/retractions-thegood-the-bad-and-the-ugly-what-researchers-stand-to-gain-from-taking-more-care-tounderstand-errors-in-the-scientific-record/

Niles , M. T., Schimanski, L. A., McKiernan, E. C., \& Alperin, J. P. (2020). Why we publish where we do: Faculty publishing values and their relationship to review, promotion and tenure expectations. PLoS ONE 15(3): e0228914. https://doi.org/10.1371/journal.pone.0228914

Haynes, B. (2020). How the Fight Against Predatory Publishing Is Gaining Momentum. IGI-Global. https://www.igi-global.com/newsroom/archive/fight-against-predatory-publishinggaining/4438/

$\mathrm{Xu}, \mathrm{X}$. (2020). The hunt for a coronavirus cure is showing how science can change for the better. The Conversation. https://theconversation.com/the-hunt-for-a-coronavirus-cure-is-showing-howscience-can-change-for-the-better-132130

Radomski, B. (2020). COVID-19 resources on ScienceOpen: Find and share research outputs. Science Open. https://blog.scienceopen.com/2020/03/covid-19-resources/ 